\title{
Chrysin inhibits cell invasion by inhibition of Recepteur d'origine Nantais via suppressing early growth response-1 and NF-кB transcription factor activities in gastric cancer cells
}

\author{
YONG XIA, SEN LIAN, PHAM NGOC KHOI, HYUN JOONG YOON, JAE YOUNG HAN, \\ KEE OH CHAY, KYUNG KEUN KIM and YOUNG DO JUNG
}

Research Institute of Medical Sciences, Chonnam National University Medical School, Gwangju 501-190, Republic of Korea

Received November 12, 2014; Accepted December 23, 2014

DOI: $10.3892 /$ ijo.2015.2847

\begin{abstract}
Cell invasion is one of crucial reasons for cancer metastasis and malignancy. Recepteur d'origine Nantais (RON) has been reported to play an important role in the cancer cell invasion process. High accumulation and activation of RON has been implicated in gastric adenocarcinoma AGS cells. Chrysin is a naturally occurring phytochemical, a type of flavonoid, which has been reported to suppress tumor metastasis. However, the effects of chrysin on RON expression in gastric cancer are not well studied. In the present study, we examined whether chrysin affects RON expression in gastric cancer, and if so, its underlying mechanism. We examined the effect of chrysin on RON expression and activity, via RT-PCR, promoter study, and western blotting in human gastric cancer AGS cells. Chrysin significantly inhibited endogenous and inducible RON expression in a dose-dependent manner. After demonstrating that Egr-1 and $\mathrm{NF}-\kappa \mathrm{B}$ are the critically required transcription factors for RON expression, we discovered that chrysin suppressed Egr-1 and NF- $\kappa \mathrm{B}$ transcription factor activities. Additionally, the phorbol-12-myristate-13-acetate(PMA) induced cell invasion was partially abrogated by chrysin and an RON antibody. Our results suggest that chrysin has anticancer effects at least by suppressing RON expression through blocking Egr-1 and NF- $\kappa \mathrm{B}$ in gastric cancer AGS cells.
\end{abstract}

\section{Introduction}

Despite its decreasing incidence over the past few decades, gastric cancer remains the most common gastrointestinal tract cancer worldwide (1). Additionally, it is still the fourth

Correspondence to: Dr Young Do Jung, Department of Biochemistry, Chonnam National University Medical School, 5 Hakdong, Gwangju 501-190, Republic of Korea

E-mail: ydjung@chonnam.ac.kr

Abbreviations: RON, Recepteur d'origine Nantais; PMA, phorbol 12-myristate 13-acetate; Egr-1, early growth response protein 1

Key words: chrysin, RON, Egr-1, NF-кB, cell invasion, gastric cancer most commonly diagnosed cancer and the second most deadly cancer $(2,3)$. Due to cancer tissue invasion and metastasis, chemotherapy and radiation therapy cannot completely cure cancer, nor significantly improve the quality of life of patients with cancer metastasis. Thus, novel therapies targeting the aberrant molecules that lead to cancer invasion or metastasis are needed.

Recepteur d'origine Nantais (RON), a member of c-Met family of scatter factor receptors, plays an important role in the progression, invasion, and metastasis of gastric carcinoma (4). RON is initially synthesized as a single chain precursor, a $170-\mathrm{kDa}$ pro-RON, which is subsequently cleaved into a $150-\mathrm{kDa} \beta$ chain and a $40-\mathrm{kDa} \alpha$ chain. The $\alpha$ chain is completely extracellular, whereas the $\beta$ chain contains the intracellular tyrosine kinase and traverses the cell membrane (5). Macrophage-stimulating protein (MSP) is the only ligand identified for RON. Through ligand binding, RON is activated and mediates multiple signaling cascades involved in cell motility, adhesion, migration, and invasion, including the mitogen-activated protein kinase (MAPK), phosphatidylinostiol-3 kinase $(\mathrm{PI} 3 \mathrm{~K}) / \mathrm{Akt}, \beta$-catenin, and nuclear factor- $\kappa \mathrm{B}$ $(\mathrm{NF}-\kappa \mathrm{B})(6)$. Several human tumor tissues show increased RON expression, including tumors of the stomach, breast, colon, lung, liver, kidney, ovary, pancreas, bladder, and prostate $(4,6,7)$. Gene expression analyses indicate that high expressions of RON are associated with metastatic cancer (8). Since RON plays an essential role in multiple processes involved in cancer progression and metastasis, it is an attractive target for RON molecular-based cancer therapy.

Because of the crucial role of RON in cancer progression and metastasis, and the multi-anticancer functions of flavonoids, it is of great significance to know the effects of flavonoids on RON expression, so that selected flavonoids can be used in cancer therapy to target the metastasis-related molecules. However, the effect of flavonoids on RON is not well studied, especially in gastric cancer cells. Thus, the aims of this study were to screen potential RON inhibitors from natural flavonoids in gastric cancer, and to examine their underlying mechanisms. Our previous study investigated and reported that EGCG, a kind of flavanol, inhibited gastric cancer cell invasion via suppression of RON expression (9). In the present study, four kinds of flavonoids, kaempferol, quer- 
cetin, genistein and chrysin were examined for an inhibitory effect on RON expression.

Kaempferol, 3,5,7-trihydroxy-2-(4-hydroxyphenyl)-4H-1benzopyran-4-one, a natural flavonol, has been isolated from tea, broccoli, Delphinium, grapefruit, cabbage, kale, beans, endive, leek, tomato, strawberries, grapes, Brussels sprouts, apples, and other plant sources (10). Kaempferol consumption in tea and broccoli has been associated with a reduced risk of heart disease (11).

Quercetin, 2-(3,4-dihydroxyphenyl)-3,5,7-trihydroxy$4 \mathrm{H}$-chromen-4-one, a kind of natural flavonol, is found in fruits, vegetables, leaves, and grains. It can be used as an ingredient in supplements, beverages, or food. Laboratory studies have investigated the potential of quercetin for use in anticancer applications $(12,13)$.

Genistein, 4',5,7-trihydroxyisoflavoneis, a phytoestrogen, belongs to the category of isoflavones. Genistein has been identified as an angiogenesis inhibitor, and has been found to inhibit the uncontrolled cell growth of cancer $(14,15)$.

Chrysin, 5,7-dihydroxyflavone, a type of naturally occurring flavonoid, has been known to inhibit tumor progression and angiogenesis $(16,17)$. It has been demonstrated that chrysin suppresses IL-6-induced angiogenesis through downregulation of the soluble interleukin- 6 receptor/gp130/JAK1/ STAT3/VEGF signaling pathway (16). Recently, chrysin was reported to inhibit insulin-induced HIF-1 $\alpha$ highly expression, increase ubiquitination of HIF-1 $\alpha$, and interfere with interaction between HIF-1 $\alpha$ and heat shock protein 90 (18).

In the four kinds of flavonoids, only chrysin effectively suppresses RON expression. Therefore, we focused on investigating the effect of chrysin on RON expression and cell invasion, and examined the underlying mechanisms, taking advantage of chrysin's ability to inhibit gastric cancer invasion via targeting RON.

\section{Materials and methods}

Cell culture and culture conditions. The AGS human gastric cancer cell line was obtained from the American Type Culture Collection (Manassas, VA, USA). The cells were cultured in RPMI-1640 (Hyclone; South Logan, UT, USA) supplemented with $10 \%$ fetal bovine serum (FBS) and $0.6 \%$ penicillin-streptomycin (Hyclone) at $37^{\circ} \mathrm{C}$ in an atmosphere containing $5 \% \mathrm{CO}_{2}$. In order to test the effect of chrysin, genistein, quercetin, kaempferol or BAY-11-7082 (BAY) on endogenous RON or Egr-1 expression, when the confluence reached $50 \%$, we co-incubated the cells with chrysin or BAY in serum-reduced (1\% FBS) RPMI-1640 media. To determine the effects of chrysin on PMA-induced RON expression, the cells were pretreated by different concentrations of chrysin and then treated by PMA. RPMI-1640, FBS, and penicillinstreptomycin were obtained from Thermo Scientific, USA. PMA, chrysin, genistein, quercetin, and kaempferol were obtained from Sigma-Aldrich, St. Louis, MO, USA; BAY was purchased from Calbiochem, Merck KGaA, Darmstadt, Germany.

Cell viability. Cells $\left(5 \times 10^{3}\right)$ were incubated in a 96-well plate with RPMI media containing 0-100 $\mu \mathrm{M}$ chrysin for $24 \mathrm{~h}$, and cell respiration was determined by an established 3-[4,5-dimethylthiazol-2-yl]c-2,5-diphenyltetrazolium bromide (MTT, Sigma-Aldrich) assay. After the cell incubation, $10 \mu \mathrm{l}$ of $5 \mathrm{mg} / \mathrm{ml} \mathrm{MTT}$ was added to each well of the 96-well plates and incubated at $37^{\circ} \mathrm{C}$ for $2 \mathrm{~h}$. The formazan granules obtained were dissolved in $100 \%$ dimethyl sulfoxide, and absorbance at $570 \mathrm{~nm}$ was detected with a 96-well ELISA reader (BioTek Instruments, Winooski, VT, USA).

Reverse transcription-PCR. Total RNA was extracted from the AGS cells using the TRIzol reagent (Invitrogen, Carlsbad, CA, USA). One microgram of total RNA was used for firststrand complementary DNA synthesis using random primers and M-MLV transcriptase (Promega, Madison, WI, USA). The complementary DNA was subjected to PCR amplification with primer sets for GAPDH and RON using PCR master mix solution (iNtRON, Korea). The specific primers sequences were as follows: GAPDH sense, 5'-TTGTTGCCATCAATGAC CCC-3' and GAPDH antisense, 5'-TGACAAAGTGGTCGTTG AGG-3' (836 bp); RON sense, 5'-ACGGCTTAGCGCCACTG AGC-3', RON antisense, 5'-CATGTGTGCCACTGTGACGT-3' (550 bp); Egr-1 sense, 5'-CAGTGGCCTAGTGAGCATGA-3', and Egr-1 antisense, 5'-CCGCAAGTGGATCTTGGTAT-3' (767 bp). The PCR conditions were as follows: denaturation at $94^{\circ} \mathrm{C}$ for $30 \mathrm{sec}$, annealing at $52^{\circ} \mathrm{C}$ for $20 \mathrm{sec}$ and extension at $72^{\circ} \mathrm{C}$ for $30 \mathrm{sec}$, repeat 32 cycles, using a Thermal Cycler (T100, Bio-Rad, USA, Hercules, CA, USA).

Western blot analysis. Cells were washed in phosphate-buffered saline (PBS), detached using trypsin-EDTA buffer, and stored at $-70^{\circ} \mathrm{C}$ until needed. The protein was extracted with RIPA buffer [1\% NP-40, $0.5 \%$ sodium deoxycholate, $0.1 \%$ sodium dodecyl sulfate (SDS)] and protease inhibitors (aprotinin, leupeptin, phenylmethanesulfonylfluoride (PMSF), benzamidine, trypsin inhibitor, and sodium orthovanadate). The protein $(50 \mu \mathrm{g})$ was then separated by $10 \%$ SDS-polyacrylamide gel electrophoresis and transferred to Immobilon-P membranes (Millipore Corp., Billarica, MA, USA). The membranes were blocked in a $0.1 \%$ Tween-20 in Tris-buffered saline (TBST) solution containing 5\% skim milk, incubated with primary antibody in a blocking solution overnight at $4^{\circ} \mathrm{C}$, and washed three times with TBST at 10 -min intervals. Horseradish peroxidase-conjugated secondary antibody (\#7074, Cell Signaling Technology, Danvers, MA, USA) 1:5000 was used to detect the immunoreactive proteins by chemiluminescence. The following primary antibodies (1:1000) were used: rabbit anti-human RON (sc-25781, Santa Cruz Biotechnology, Inc., CA, USA), rabbit anti-human Egr-1 (sc-110, Santa Cruz), rabbit anti-human phospho-NF-кB-p65 (\#3033, Cell Signaling Technology) and rabbit anti-human phospho-IкB $\alpha$ (\#9241, Cell Signaling Technology). The total protein levels were assayed by washing the blotted membrane with a stripping solution composed of $100 \mathrm{mM}$ 2-mercaptoethanol, 2\% SDS, and $62.5 \mathrm{mM}$ Tris- $\mathrm{HCl}(\mathrm{pH} 6.7)$ for $30 \mathrm{~min}$ at $50^{\circ} \mathrm{C}$, and the membrane was then re-probed with either anti- $\beta$-actin (\#4967, Cell Signaling Technology) or rabbit antihuman IкB $\alpha$ (\#9242, Cell Signaling Technology).

RON promoter reporter construct. The sequence of RON promoter fragment, approximately $3 \mathrm{~kb}$ in length, was synthesized from human genomic DNA (Promega) by PCR using the 
A<smiles>O=c1cc(-c2ccccc2)oc2cc(O)cc(O)c12</smiles><smiles>O=c1c(O)c(-c2ccc(O)cc2)oc2cc(O)cc(O)c12</smiles><smiles></smiles>

Quercetin
Kaempferol<smiles>O=c1c(-c2ccc(O)cc2)coc2cc(O)cc(O)c12</smiles>

Genistein
B

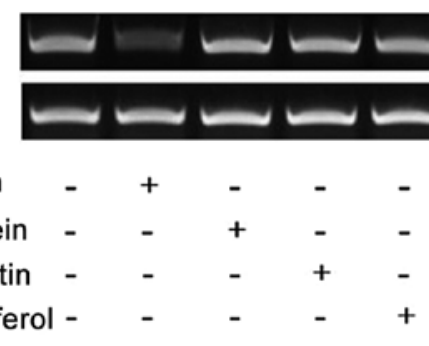

RON

GAPDH
C

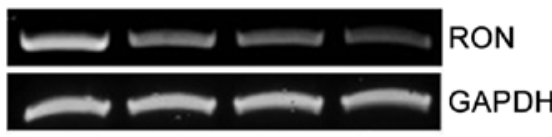

Chrysin $(\mu \mathrm{M}) \quad 0 \quad 20 \quad 40 \quad 60$

$\mathbf{E}$

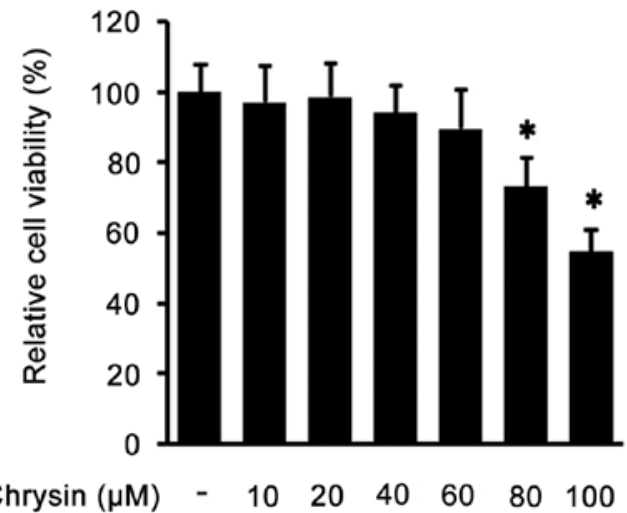

primer 5'-GGTACCTAGCTGACC-3' (forward) and 5'-GGG CCAAATTTAAGC-3' (reverse). The amplified PCR products were ligated into the T\&A Vector (RBC Bioscience, Saskatoon, $\mathrm{SK}$, Canada), and then digested with restriction endonuclease $K p n I$ and $B g l$ II (Takara, Japan). The products were ligated into the KpnI and BglII sites of the pGL3-Basic Vector (Promega). The final construct was the RON promoter reporter (pGL3-RON).

Measurement of RON promoter activity. The transcriptional regulation of RON was examined by the transient transfection of a RON promoter-luciferase reporter construct (pGL3-RON). AGS cells were seeded and grown until they reached $70 \%$ confluence. Then, the pGL3-RON promoter plasmids were transfected into the cells using FuGENE 6 (Promega) according to the manufacturer's protocol. PRL-TK was transfected as an internal control. Cells were incubated in the transfection medium for $12 \mathrm{~h}$ and then treated with PMA for $4 \mathrm{~h}$. The effects of chrysin on RON promoter activity were determined by pretreating cells with chrysin for $1 \mathrm{~h}$ prior to the addition of PMA. Co-transfection studies were performed
Figure 1. Chrysin inhibits endogenous RON in gastric cancer AGS cells. The molecular structures of chrysin, kaempferol, quercetin and genistein are shown (A). When cell confluence was $50 \%$, cells were incubated with $25 \mu \mathrm{M}$ chrysin, genistein, quercetin and kaempferol for $24 \mathrm{~h}$ in RPMI with $1 \%$ FBS. After incubation, RON mRNA in the cell lysates was examined by RT-PCR (B). Cells were incubated with 0-60 $\mu \mathrm{M}$ chrysin for $24 \mathrm{~h}$ in RPMI with $1 \%$ FBS. Then, RON mRNA was tested by RT-PCR (C); and RON protein was tested by western blotting (D). The cells were co-incubated with $0-100 \mu \mathrm{M}$ chrysin for $24 \mathrm{~h}$, and then the viability was tested by the MTT method. The data represent the mean \pm SD from triplicate measurements. ${ }^{*} \mathrm{P}<0.05$ versus control (without chrysin) (E).

in the presence or absence of the expression vector encoding the full length cDNA coding human Egr-1, which was kindly provided by Dr Young Han Lee (Konkuk University, Seoul, Korea). Additionally, in order to check the role of $\mathrm{NF}-\kappa \mathrm{B}$ on RON expression, the co-transfection studies were performed in the presence or absence of the expression vector encoding the dominant negative mutant IKK $\alpha$, IKK $\beta$, or NIK, which were kindly provided by Dr D.W. Ballard (19) and W.C. Greene (20). The cells were harvested with a Cell Culture Lysis reagent (Promega), and the luciferase activities were determined using a luminometer (Centro XS lb960 Microplate Luminometer, Berthold Technologies, USA) according to the manufacturer's protocol.

Transient transfection of Egr-1 promoter reporter. The Egr-1 promoter reporter plasmid was kindly provided by Dr Young Han Lee (Konkuk University). When AGS cells reached $60-70 \%$ confluence, they were washed by Opti-MEM medium and transfected with a pGL-3 vector containing the Egr-1 promoter reporter using FuGENE 6 (Promega) according to the manufacturer's protocol. Reporter-transfected cells were 
pretreated with chrysin for $1 \mathrm{~h}$, treated with $100 \mathrm{nM}$ PMA for $4 \mathrm{~h}$, and then luciferase activity was measured using a luminometer.

Transient transfection of $N F-\kappa B$ reporter. The $\mathrm{NF}-\kappa \mathrm{B}$ reporter plasmid was purchased from Clontech (Palo Alto, CA, USA). AGS cells were washed in Opti-MEM medium and transfected with the pGL-3-NF- $\kappa$ B reporter plasmid using FuGENE 6 (Promega) according to the manufacturer's protocol. Reportertransfected cells were pretreated with chrysin for $1 \mathrm{~h}$, treated with $100 \mathrm{nM}$ PMA for $4 \mathrm{~h}$, and then the luciferase activity was measured using a luminometer.

Small interfering RNA transfection. Gene silencing was performed by using human Egr-1 (sc-29303, Santa Cruz) and RON sequence-specific duplex siRNA (sc-36434, Santa Cruz). Briefly, for each transfection reaction in two separate tubes, $20 \mathrm{nM}$ siRNA oligonucleotides and $2 \mu \mathrm{l}$ Lipofectamine RNAi MAX (Invitrogen) were respectively mixed with $100 \mu 1$ serum-free Optimem (Hyclone). Then, we mixed the two tubes, incubating for $5 \mathrm{~min}$ at room temperature to form the RNA-lipofectamine complex, and then they were added to cell plates with Opti-MEM medium. After incubation for $6 \mathrm{~h}$, the medium was replaced with normal growth medium.

Matrigel invasion assay. The cell invasion assay was carried out using the 10-well chemotasis chamber (Neuro Probe, USA) with $8 \mu \mathrm{M}$ membrane pore (Neuro Probe) with $10 \%$ FBS containing RPMI as the chemoattractant in the lower chamber. AGS cells $\left(10^{5}\right)$ in $250 \mu \mathrm{l}$ were added to upper chamber with PMA with the presence of chrysin or RON antibody and allowed to invade the Matrigel for $24 \mathrm{~h}$. The non-invading cells on the upper surface of each membrane were removed from the chamber with a cotton swab, and the invading cells on the lower surface of each membrane were stained with the Quick-Diff kit (Becton-Dickinson, Franklin Lakes, NJ, USA). After two washes with water, the chambers were allowed to air-dry. The number of invading cells was counted using a phase-contrast microscope (Olympus IX50, Japan).

Statistics. Data are shown as mean $\pm \mathrm{SD}$, and represent the mean of at least three separate experiments performed in triplicate. Differences between data sets were determined by the t-test. Differences described as significant in the text correspond to $\mathrm{P}<0.05$.

\section{Results}

Chrysin inhibits endogenous RON in gastric cancer AGS cells. To determine the effect of flavones in endogenous RON expression in human gastric cancer AGS cells, the cells were incubated with chrysin, genistein, quercetin, and kaempferol (Fig. 1A), and the levels of RON mRNA were determined by RT-PCR analysis. Interestingly, as shown in Fig. 1B, among the four flavonoids, only chrysin inhibited RON expression in AGS cells. Next, we verified the inhibitory effect of chrysin against RON expression by incubating the cells with different concentration of chrysin. The RT-PCR results showed that chrysin decreases RON mRNA in a dose-dependent manner (Fig. 1C). Additionally, western blotting result showed
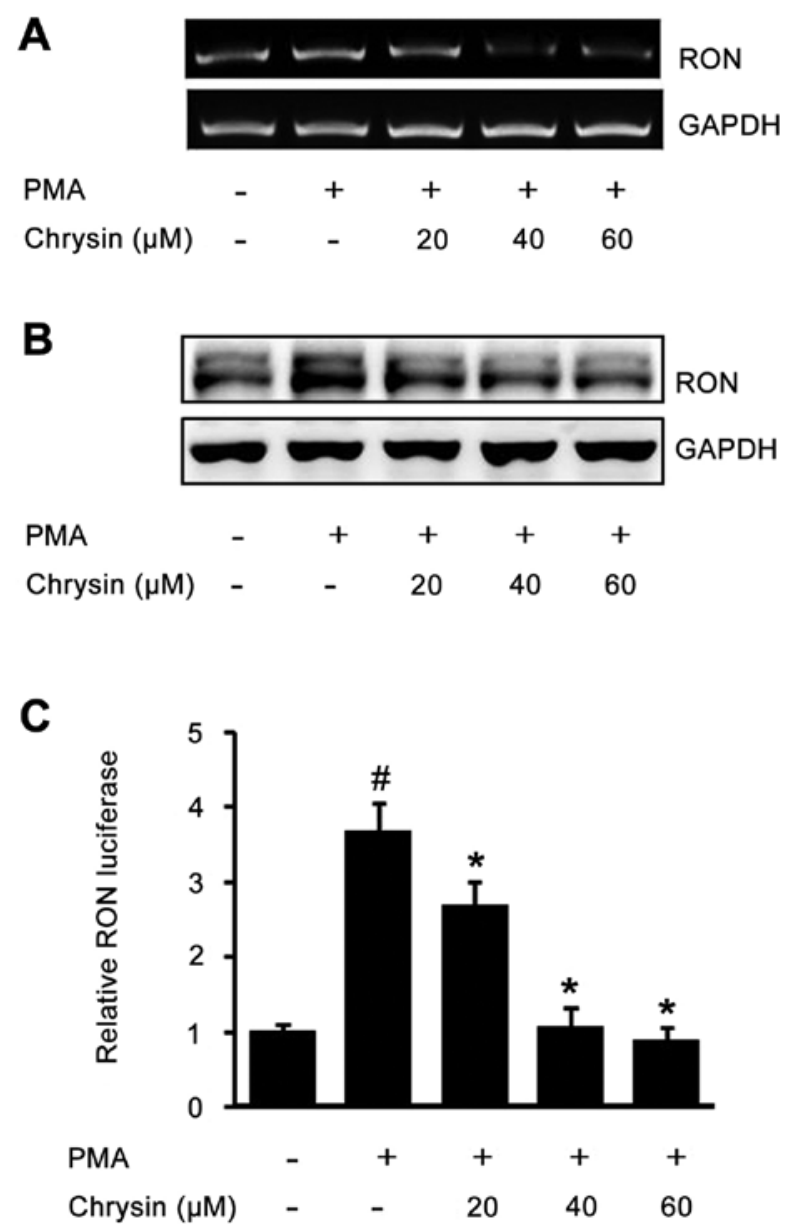

Figure 2. Chrysin inhibits PMA-induced RON in gastric cancer AGS cells. Cells pretreated with the indicated concentrations of chrysin for $1 \mathrm{~h}$ were treated with $100 \mathrm{nM}$ PMA. After PMA treatment, RT-PCR was performed to analyze the RON mRNA (A); and western blotting was performed to analyze the RON- $\beta$ protein level (B). The pGL3-RON promoter construct transfected cells were pretreated with the indicated concentrations of chrysin for $1 \mathrm{~h}$, then were incubated with $100 \mathrm{nM}$ PMA for $4 \mathrm{~h}$ and luciferase activity was determined using a luminometer. The data represent the mean \pm SD from triplicate measurements. ${ }^{\#} \mathrm{P}<0.05$ versus control; ${ }^{*} \mathrm{P}<0.05$ versus $\mathrm{PMA}$ only $(\mathrm{C})$.

that chrysin decreased RON protein in a dose-dependent manner (Fig. 1D). Collectively, these results demonstrated that chrysin suppresses the expression of endogenous RON in human gastric cancer AGS cells. The concentrations of chrysin used in the above study did not affect cell viability (Fig. 1E). These results indicated that chrysin inhibited endogenous RON expression in a dose-dependent manner in AGS cells.

Chrysin inhibits PMA-induced RON in gastric cancer AGS cells. In order to test the suppressive effect of chrysin against inducible RON, AGS cells pretreated with chrysin were incubated with PMA, and then RT-PCR and western blot analysis were performed. PMA-induced RON mRNA was inhibited by chrysin in a dose-dependent manner (Fig. 2A). Additionally, the PMA-upregulated RON protein was also suppressed by chrysin in a dose-dependent manner (Fig. 2B). Next, we checked the inhibitory effect of chrysin against RON through a promoter activity assay. As shown in Fig. 2C, 
A

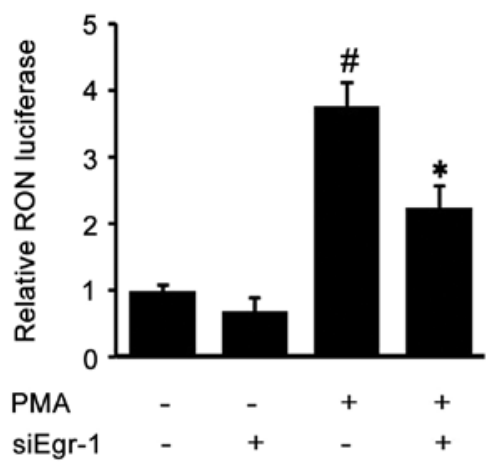

B

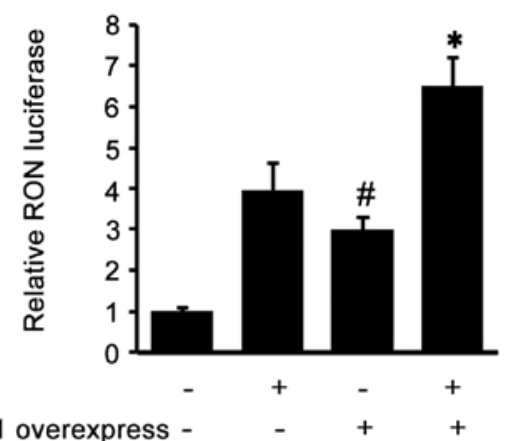

D

PMA

Egr-1 overexpress - $\quad-\quad+\quad+$

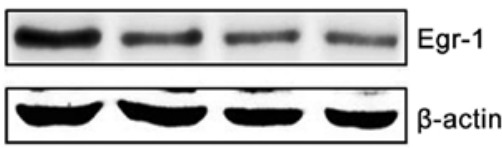

GAPDH

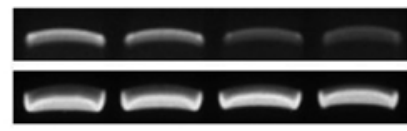

60

Chrysin $(\mu \mathrm{M})$

20

40

60

E

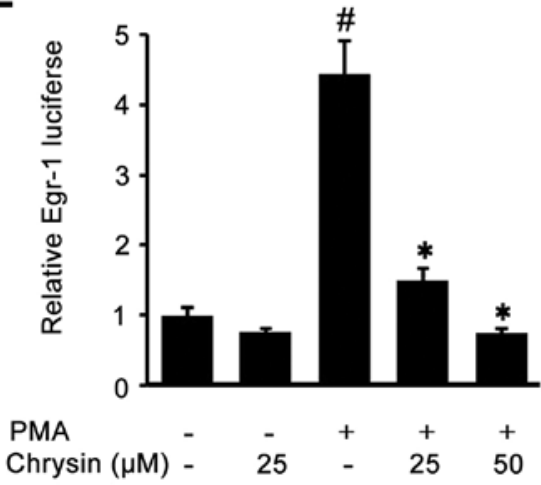

F

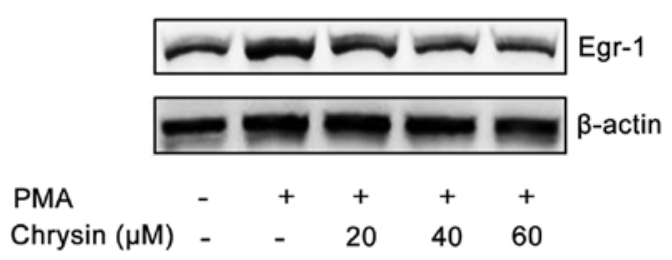

Figure 3. The role of Egr-1 in the inhibition of RON by chrysin in gastric cancer AGS cells. The Egr-1 siRNA was co-transfected with pGL3-RON promoter construct into AGS cells. After incubation with $100 \mathrm{nM}$ PMA for $4 \mathrm{~h}$, the luciferase activity was determined using a luminometer. The data represent the mean \pm SD from triplicate measurements. ${ }^{*} \mathrm{P}<0.05$ versus control; ${ }^{*} \mathrm{P}<0.05$ versus PMA only (A). Egr-1 overexpression construct was co-transfected with a pGL3RON promoter construct into AGS cells. The transfected cells pretreated with or without chrysin for $1 \mathrm{~h}$ were incubated with $100 \mathrm{nM}$ PMA for $4 \mathrm{~h}$, and then the RON-luciferase activity was determined using a luminometer. " $\mathrm{P}<0.05$ versus control; " $\mathrm{P}<0.05$ versus PMA only (B). AGS cells were incubated with $0-60 \mu \mathrm{M}$ chrysin for $24 \mathrm{~h}$ in RPMI with $1 \%$ FBS. Then endogenous Egr-1 mRNA was tested by RT-PCR (C); and the endogenous Erg-1 protein was tested by western blotting (D). The Egr-1-luciferase reporter construct transfected cells were pretreated with the indicated concentrations of chrysin for $1 \mathrm{~h}$, then incubated with $100 \mathrm{nM}$ PMA for $4 \mathrm{~h}$ and the Erg-1 luciferase activity was determined using a luminometer. The data represent the mean \pm SD from triplicate measurements. ${ }^{\text {"}} \mathrm{P}<0.05$ versus control; ${ }^{*} \mathrm{P}<0.05$ versus PMA only (E). Cells pretreated with the indicated concentrations of chrysin for $1 \mathrm{~h}$ were treated with $100 \mathrm{nM}$ PMA for $8 \mathrm{~h}$. After incubation, western blotting was performed to analyze the Erg-1 protein $(\mathrm{F})$.

the activated RON promoter was suppressed by chrysin in a dose-dependent manner. The above results demonstrated that chrysin inhibits the PMA-induced RON in human gastric cancer AGS cells.

Role of Egr-1 in the inhibition of RON by chrysin in gastric cancer AGS cells. To check the role of Egr-1 on RON expression, AGS cells were transiently co-transfected with siEgr-1 and RON promoter reporter (pGL-3-RON), and then the cells were treated with PMA. As shown in Fig. 3A, the siEgr-1-transfected cells showed lower RON promoter activity in both PMA-treated cells and untreated cells. Next, we verified the role of Egr-1 on RON expression by co-transfecting the Egr-1 expression construct and pGL-3-RON. As shown in Fig. 3B, the cells transfected with the Egr-1 expression construct showed higher RON promoter activity in both PMA-treated cells and untreated cells. Fig. 3A and B demonstrated that Egr-1 played a crucial role in RON expression. So, we hypothesized that chrysin may inhibit RON by inhibiting Egr-1. To test this hypothesis, we checked the effect of chrysin on endogenous Egr-1. After incubating cells with different concentration of chrysin, RT-PCR and western blotting were performed to check the Egr-1 mRNA and protein levels. As shown in Fig. 3C and D, chrysin suppressed endogenous Egr-1 mRNA and protein in a dose-dependent manner. Subsequently, in order to check the effect of chrysin on inducible Egr-1 activity, we transfected the Egr-1 reporter construct and stimulated the cells with PMA. PMA drastically induced Egr-1 reporter luciferase activity, which was inhibited by chrysin (Fig. 3E). Finally, to examine the inhibitory effect of chrysin on PMA-induced 
A

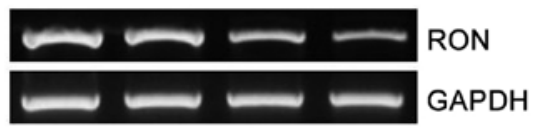

$\operatorname{BAY}(\mu \mathrm{M}) \quad-\quad 10 \quad 20 \quad 40$

C

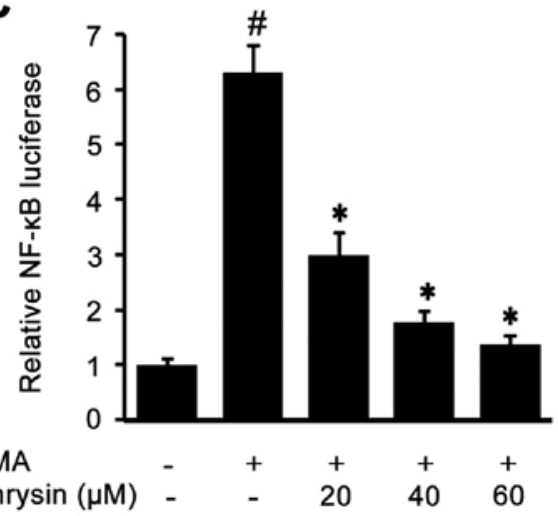

E

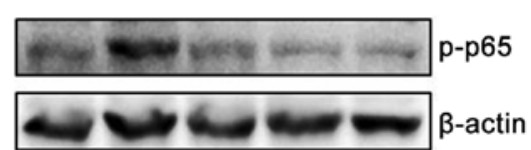

PMA

Chrysin $(\mu \mathrm{M})$ - $\quad$ - 204060
B

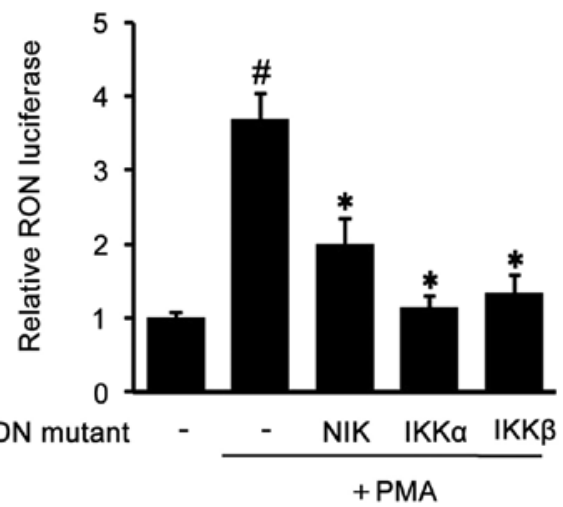

D

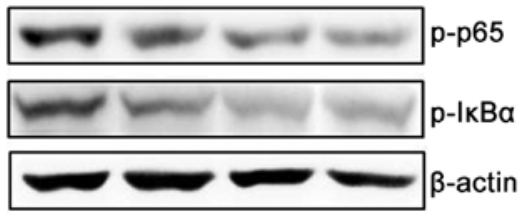

Chrysin $(\mu \mathrm{M}) \quad-\quad 20 \quad 40 \quad 60$

F

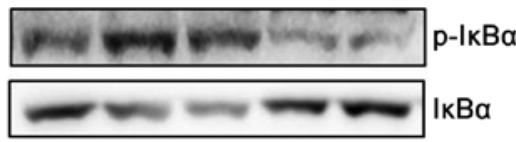

PMA

Chrysin $(\mu \mathrm{M}) \quad-\quad$ - $20 \quad 40 \quad 60$

Figure 4. The role of NF-kB in the inhibition of RON by chrysin in gastric cancer AGS cells. When cell confluence was $50 \%$, they were incubated with the indicated concentrations of BAY-11-7082 (BAY) for $24 \mathrm{~h}$ in RPMI with 1\% FBS. After incubation, RON mRNA was examined by RT-PCR (A). An expression vector encoding dominant negative mutant NIK, IKK $\alpha$, IKK $\beta$, or empty vector was co-transfected with a pGL-3-RON promoter construct into AGS cells. After incubation with $100 \mathrm{nM}$ PMA for $4 \mathrm{~h}$, the luciferase activity was determined using a luminometer. The data represent the mean \pm SD from triplicate measurements. ${ }^{*} \mathrm{P}<0.05$ versus control; ${ }^{*} \mathrm{P}<0.05$ versus PMA only (B). The NF- $\mathrm{kB}$-luciferase reporter construct transfected cells were pretreated with the indicated concentrations of chrysin for $1 \mathrm{~h}$, then they were incubated with $100 \mathrm{nM}$ PMA for $4 \mathrm{~h}$ and the NF-kB luciferase activity was determined using a luminometer. The data represent the mean $\pm \mathrm{SD}$ from triplicate measurements. ${ }^{\#} \mathrm{P}<0.05$ versus control; " $\mathrm{P}<0.05$ versus PMA only (C). When the confluence of cells was $50 \%$, they were incubated with the indicated concentrations of chrysin for $24 \mathrm{~h}$ in RPMI media containing $1 \%$ FBS. After cell harvest, western blotting was employed to examine the phosphorylated p65 and IкB $\alpha$ (D). AGS cells pretreated with the indicated concentrations of chrysin for $1 \mathrm{~h}$ were treated with $100 \mathrm{nM}$ PMA for $15 \mathrm{~min}$. After incubation, western blotting was performed to analyze the phosphorylated NF-kB p65 (E); as well as phosphorylated $\mathrm{I} \kappa \mathrm{B} \alpha$ and total $\mathrm{I} \kappa \mathrm{B} \alpha(\mathrm{F})$.

Egr-1 expression, western blotting was employed. As shown in Fig. 3F, chrysin inhibited PMA-upregulated Egr-1 protein in a dose-dependent manner. These results indicated that one of the chrysin mechanisms of inhibition of RON is through the suppression of Egr-1, a critically required transcription factor of RON expression.

Role of $N F-\kappa B$ in the inhibition of RON by chrysin in gastric cancer AGS cells. To check the role of transcription factor $\mathrm{NF}-\kappa \mathrm{B}$ on RON expression, we first treated the cells with different concentrations of NF- $\kappa \mathrm{B}$ inhibitor BAY-11-7082. As shown in Fig. 4A, BAY decreased endogenous RON expression, indicating that $\mathrm{NF}-\kappa \mathrm{B}$ may play an important role in RON expression. To further confirm the role of NF- $\kappa$ B on RON expression, dominant negative mutant expression constructs were co-transfected with pGL-3-RON into AGS cells. As shown in Fig. 4B, the expression of dominant negative mutant forms of NIK, IKK- $\alpha$ and IKK- $\beta$, resulted in a decrease of PMA-induced RON promoter activity indicating the essential role of NF- $\kappa \mathrm{B}$ on RON expression. Next, we checked whether chrysin was able to affect NF- $\kappa$ B by transfection of a pGL3$\mathrm{NF}-\kappa \mathrm{B}$ luciferase construct. As shown in Fig. 4C, chrysin inhibited PMA-induced NF- $\kappa \mathrm{B}$ activity in a dose-dependent manner. Subsequently, to check the effect of chrysin on $\mathrm{NF}-\kappa \mathrm{B}-$ related proteins p 65 and $\mathrm{I} \kappa \mathrm{B} \alpha$, western blotting was performed: chrysin inhibited the endogenous phosphorylated $\mathrm{NF}-\kappa \mathrm{B}$ p65 and I $\mathrm{B} \alpha$ (Fig. 4D); and the PMA-induced NF- $\kappa \mathrm{B}$ p65 and $\mathrm{I} \kappa \mathrm{B} \alpha$ phosphorylation was also suppressed by chrysin in a dose-dependent manner (Fig. 4E and F).

Chrysin inhibits gastric cancer AGS cell invasion. Since chrysin could decrease endogenous RON, the effect of chrysin in AGS cell invasion was checked with a modified Boyden Chamber method. As shown in Fig. 5A, the cells co-incubated 
A
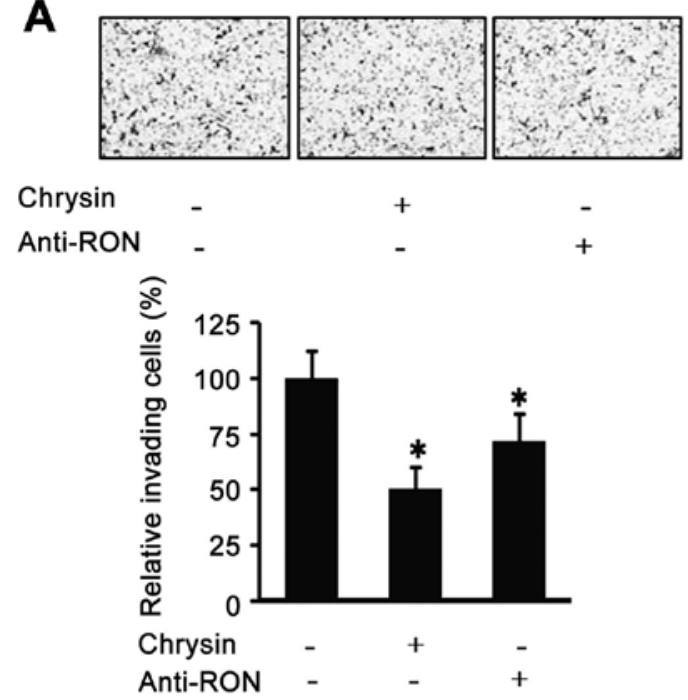

C

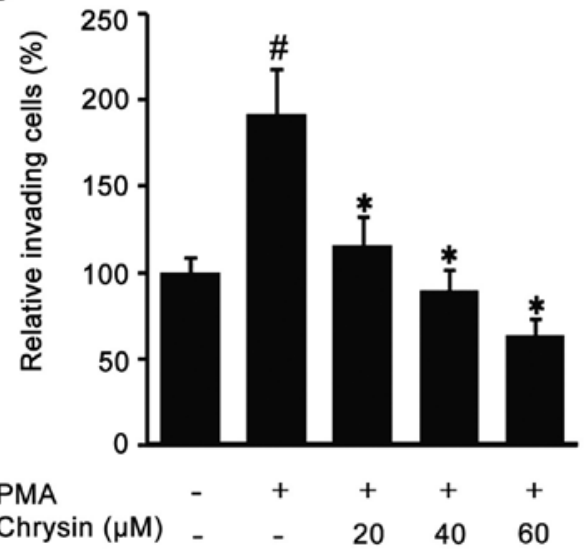

B

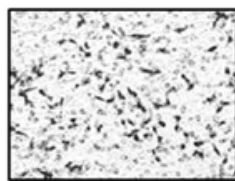

Control

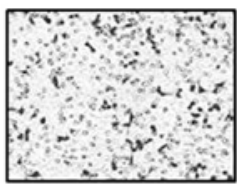

PMA+chrysin

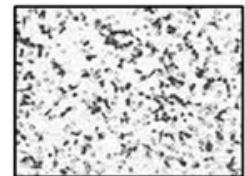

PMA

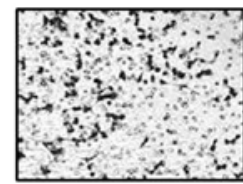

PMA+anti-RON

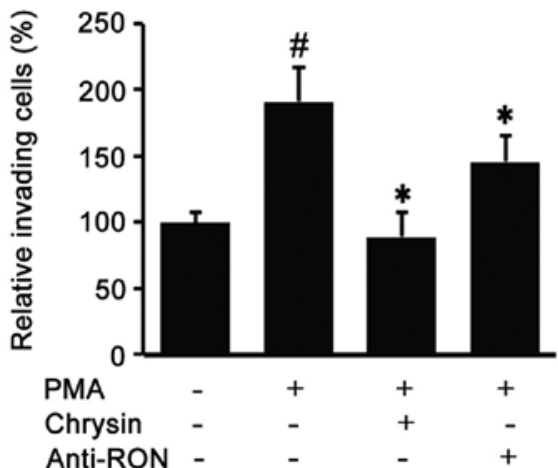

D

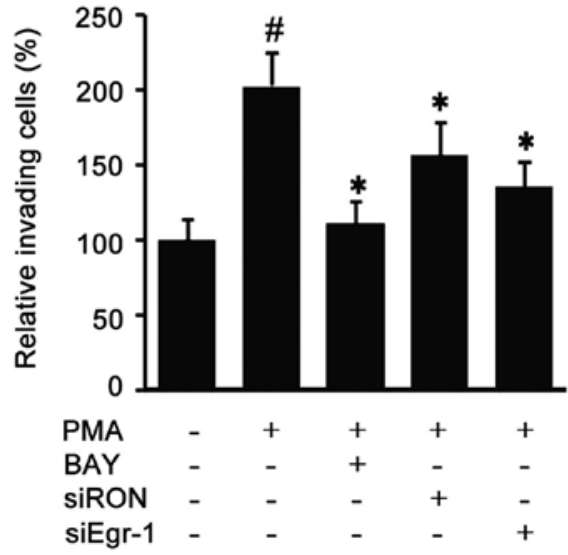

Figure 5. Chrysin inhibits AGS cells invasion by suppressing RON expression. Cells were incubated with $40 \mu \mathrm{M}$ chrysin or $200 \mathrm{ng} / \mathrm{ml} \mathrm{RON}$ antibody for $24 \mathrm{~h}$ in a BioCoat ${ }^{\mathrm{TM}}$ Matrigel apparatus with $8 \mu \mathrm{M}$ pore membrane for $24 \mathrm{~h}$. After incubation, the cells that invaded the lower surface of the chambers were counted using a phase contrast light microscope after staining with a Diff-Quick Stain kit. "P $<0.05$ versus control (A). Cells were incubated with $50 \mathrm{nM}$ PMA at the presence or absence of $40 \mu \mathrm{M}$ chrysin or $200 \mathrm{ng} / \mathrm{ml}$ RON antibody in BioCoat Matrigel apparatus for $24 \mathrm{~h}(\mathrm{~B})$. Cells were incubated with $50 \mathrm{nM}$ PMA at the presence of 0-60 $\mu \mathrm{M}$ chrysin or $200 \mathrm{ng} / \mathrm{ml}$ RON antibody (C). Cells transfected by Si Egr-1 or Si RON, or pretreated by $10 \mu \mathrm{M}$ BAY were incubated with $50 \mathrm{nM}$ PMA for $24 \mathrm{~h}$ (D). After incubation, the cells that invaded the lower surface of the chambers were counted using a phase contrast light microscope after staining with a Diff-Quick Stain kit. The data represent the mean \pm SD from triplicate measurements. ${ }^{\prime \prime} \mathrm{P}<0.05$ versus control; " $\mathrm{P}<0.05$ versus $\mathrm{PMA}$ only.

with chrysin or RON antibody had decreased the Matrigel invasiveness. Additionally, because it has been suggested that highly expressed RON is important for the invasive phenotype of cancer cells, the role of PMA-induced RON in AGS cell invasion was evaluated with a modified Boyden Chamber method. As shown in Fig. 5B, the PMA-induced cell invasion was suppressed by chrysin and RON antibody. Fig. 5C indicates that chrysin suppressed PMA-induced invasion in a dose-dependent manner. Additionally, BAY-treated cells partially lost their PMA-induced invasiveness and the si-Egr-1 and si-RON transfected cells also showed lower invasiveness (Fig. 5D). These results suggest that chrysin may reduce cancer invasiveness via the suppression of RON expression.

\section{Discussion}

RON is a kind of tyrosine kinase receptor which regulates multiple processes involved in tumor progression and metastasis $(21,22)$. Generally, RON is relatively low in normal cells. However, the levels of RON expression in malignant cancer 
cells increase several-fold compared with normal cells. The aberrant expression of RON has been observed in many kinds of cancer cells, and is associated with malignancy and poor clinical outcome in various cancers including gastric cancer $(7,23)$. Because of the importance of RON in cancer initiation and progression, more and more investigators are considering RON to be an important therapeutic target.

In this study, which focused on the inhibition of RON, we demonstrated that chrysin inhibited both endogenous and inducible RON expression by regulating Egr- 1 and NF- $\mathrm{\kappa B}$ in gastric cancer cells, and that these events may contribute to develop a new cancer therapy. The reasons we are interested in chrysin as an anticancer agent, are the following: i) chrysin is a naturally occurring flavone with low cytotoxicity (24); ii) it was discovered that chrysin has an anti-inflammation function, such as inhibition of COX-2 (25) and TNF- $\alpha$ (26); iii) chrysin reduces the proliferation and induces apoptosis in the various cancers, such as prostate cancer cells (27) and leukemia cells (28); iv) in our preliminary experiment, among the four flavonoids, chrysin was unique in its ability to inhibit RON expression. Although chrysin administration inhibits carcinogenesis using several mechanisms, our present finding, in a novel angle, suggests that chrysin may exert its anti-invasion effects by inhibiting RON expression.

Previously, we investigated the role of RON in the course of gastric cancer cell invasion and we identified the essential regulatory elements of Egr-1 that are critically required for oncogenic RON expression (4). Egr-1 is an inducible early response transcription factor that recognizes $9 \mathrm{bp}$ targeting DNA sites via three zinc finger domains and activates genes in response to cellular stimuli such as cytokines, growth factors, synaptic signals, and vascular stress, and modulates cell proliferation, inflammation, and apoptosis in various cells $(29,30)$. In the present study, using the Egr-1 siRNA and Egr-1 expression construct, we confirmed the essential role of Egr-1 for RON gene transcription. Interestingly, chrysin suppressed the Egr-1 mRNA and protein, as well as the Egr-1 transcription factor activity (Fig. 3C-F), indicating that the interruption of Egr-1 by chrysin plays a critical role in suppressing RON gene expression. This result is consistent with the previous report that genistein, a flavone with a similar structure to chrysin, inhibits the surface $\operatorname{IgM}$ and $\operatorname{IgD}$-crosslinking-induced Egr-1 expression in a dose-dependent manner in the human B lymphoma cell line B104 (31).

Besides Egr-1, we found that NF- $\mathrm{KB}$ is another essential transcription factor involved in RON expression regulation. $\mathrm{NF}-\mathrm{kB}$, a protein complex that controls DNA transcription, is found in almost all animal cell types and is involved in cellular responses to stimuli, such as stress, cytokines, and free radicals, and plays a key role in regulating the immune response to infection. Incorrect regulation of NF- $\mathrm{KB}$ has been linked to inflammatory, and autoimmune diseases, and cancer (32-34). Consistent with that reported by Narasimhan and Ammanamanchi, there are two putative NF- $\kappa \mathrm{B}$ p65 subunit binding sites on the RON promoter (35), and we also demonstrated that NF- $\kappa \mathrm{B}$ is critically required for RON gene transcription through a specific inhibitor and dominant negative plasmid transfection assays (Fig. 4A and B). We found chrysin suppressed PMA-induced NF- $\mathrm{KB}$ activity by inhib-

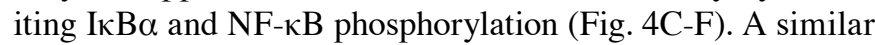

finding was reported, that chrysin inhibited the activation of $\mathrm{NF}-\mathrm{KB}$, which is involved in regulation of the iNOS and COX-2 in BV-2 microglia cells (36). We infer that the mechanism of chrysin inhibiting NF- $\kappa \mathrm{B}$ may be through the inactivation of I $\kappa \mathrm{B}$ kinase (IKK). Another report is consistent with our hypothesis: apigenin and luteolin, two kinds of flavones with similar structures to chrysin, inhibit IкB $\alpha$ degradation, NF- $\kappa B$ DNA-protein binding, and NF- $\kappa B$ luciferase activity via actively inhibiting IKK activity (37).

Concluding, this study finds that chrysin is able to suppress RON expression and cell invasion in gastric cancer AGS cells, which suggests that the downregulation of RON by chrysin is involved in decreasing cell invasion. The inhibition mechanism may be that chrysin inhibits RON expression by suppressing the activation of transcription factor Egr-1 and NF- $\mathrm{kB}$. However, we did not exclude other possible mechanisms. These findings may provide useful evidence for developing new anticancer therapeutics for gastric cancer.

\section{Acknowledgements}

This study was supported by a research grant (0720570) from the National Cancer Center, by a Basic Science Research Program grant through the National Research Foundation of Korea (NRF) funded by the Ministry of Education, Science, and Technology (2010-0009910), and by a Medical Research Center (2012-000-9442) grant from the Korean Science and Engineering Foundation.

\section{References}

1. Yamashita K, Sakuramoto S, Nemoto M, Shibata T, Mieno H, Katada N, Kikuchi S and Watanabe M: Trend in gastric cancer: 35 years of surgical experience in Japan. World J Gastroenterol 17: 3390-3397, 2011.

2. Jemal A, Center MM, DeSantis C and Ward EM: Global patterns of cancer incidence and mortality rates and trends. Cancer Epidemiol Biomarkers Prev 19: 1893-1907, 2010.

3. Orditura M, Galizia G, Sforza V, Gambardella V, Fabozzi A, Laterza MM, Andreozzi F, Ventriglia J, Savastano B and Mabilia A: Treatment of gastric cancer. World J Gastroenterol 20: 1635-1649, 2014.

4. Lee KE, Park JS, Khoi PN, Joo YE, Lee YH and Jung YD: Upregulation of Recepteur d'origine Nantais tyrosine kinase and cell invasiveness via early growth response-1 in gastric cancer cells. J Cell Biochem 113: 1217-1223, 2012.

5. Wang MH, Lee W, Luo YL, Weis M and Yao HP: Altered expression of the RON receptor tyrosine kinase in various epithelial cancers and its contribution to tumourigenic phenotypes in thyroid cancer cells. J Pathol 213: 402-411, 2007.

6. Kim S, Yoon TM, Lee DH, Park Y-L, Lee K-H, Lim SC, Joo Y-E and Lee JK: RON (Recepteur d'origine Nantais) expression and its association with tumor progression in laryngeal squamous cell carcinoma. Auris Nasus Larynx 41: 201-206, 2014.

7. Leonis MA, Thobe MN and Waltz SE: Ron-receptor tyrosine kinase in tumorigenesis and metastasis. Future Oncol 3: 441-448, 2007.

8. Thangasamy A, Rogge $\mathbf{J}$ and Ammanamanchi S: Recepteur d'origine Nantais tyrosine kinase is a direct target of hypoxiainducible factor-1 $\alpha$-mediated invasion of breast carcinoma cells. J Biol Chem 284: 14001-14010, 2009.

9. Park JS, Khoi PN, Joo YE, Lee YH, Lang SA, Stoeltzing O and Jung YD: EGCG inhibits Recepteur d'origine Nantais expression by suppressing Egr-1 in gastric cancer cells. Int J Oncol 42: 1120-1126, 2013.

10. Lin C-W, Chen P-N, Chen M-K, Yang W-E, Tang C-H, Yang S-F and Hsieh Y-S: Kaempferol reduces matrix metalloproteinase-2 expression by down-regulating ERK1/2 and the activator protein-1 signaling pathways in oral cancer cells. PLoS One 8: e80883, 2013. 
11. Calderon-Montano JM, Burgos-Morón E, Pérez-Guerrero C and López-Lázaro M: A review on the dietary flavonoid kaempferol. Mini Rev Med Chem 11: 298-344, 2011.

12. Murakami A, Ashida $\mathrm{H}$ and Terao J: Multitargeted cancer prevention by quercetin. Cancer Lett 269: 315-325, 2008.

13. Lin C-W, Hou W-C, Shen S-C, Juan S-H, Ko C-H, Wang L-M and Chen Y-C: Quercetin inhibition of tumor invasion via suppressing $\mathrm{PKC} / \mathrm{ERK} / \mathrm{AP}-1$-dependent matrix metalloproteinase- 9 activation in breast carcinoma cells. Carcinogenesis 29 : $1807-1815,2008$.

14. Nakamura Y, Yogosawa S, Izutani Y, Watanabe H, Otsuji E and Sakai T: A combination of indol-3-carbinol and genistein synergistically induces apoptosis in human colon cancer HT-29 cells by inhibiting Akt phosphorylation and progression of autophagy. Mol Cancer 8: 1476-4598, 2009.

15. Kim SH, Kim SH, Kim YB, Jeon YT, Lee SC and Song YS: Genistein inhibits cell growth by modulating various mitogenactivated protein kinases and AKT in cervical cancer cells. Ann NY Acad Sci 1171: 495-500, 2009.

16. Lin C-M, Shyu K-G, Wang B-W, Chang H, Chen Y-H and Chiu J-H: Chrysin suppresses IL-6-induced angiogenesis via down-regulation of JAK1/STAT3 and VEGF: an in vitro and in ovo approach. J Agric Food Chem 58: 7082-7087, 2010.

17. Lirdprapamongkol K, Sakurai H, Abdelhamed S, Yokoyama S, Maruyama T, Athikomkulchai S, Viriyaroj A, Awale S, Yagita H and Ruchirawat S: A flavonoid chrysin suppresses hypoxic survival and metastatic growth of mouse breast cancer cells Oncol Rep 30: 2357-2364, 2013.

18. Fu B, Xue J, Li Z, Shi X, Jiang B-H and Fang J: Chrysin inhibits expression of hypoxia-inducible factor- $1 \alpha$ through reducing hypoxia-inducible factor- $1 \alpha$ stability and inhibiting its protein synthesis. Mol Cancer Ther 6: 220-226, 2007.

19. McKinsey TA, Brockman JA, Scherer DC, Al-Murrani SW, Green PL and Ballard DW: Inactivation of IkappaBbeta by the tax protein of human T-cell leukemia virus type 1: a potential mechanism for constitutive induction of NF-kappaB. Mol Cell Biol 16: 2083-2090, 1996.

20. Geleziunas R, Ferrell S, Lin X, Mu Y, Cunningham ET, Grant M, Connelly MA, Hambor JE, Marcu KB and Greene WC: Human T-cell leukemia virus type 1 Tax induction of NF- $\mathrm{KB}$ involves activation of the IкB kinase $\alpha(\mathrm{IKK} \alpha)$ and IKK $\beta$ cellular kinases. Mol Cell Biol 18: 5157-5165, 1998 .

21. Snuderl M, Fazlollahi L, Le LP, Nitta M, Zhelyazkova BH, Davidson CJ, Akhavanfard S, Cahill DP, Aldape KD and Betensky RA: Mosaic amplification of multiple receptor tyrosine kinase genes in glioblastoma. Cancer Cell 20: 810-817, 2011.

22. Lemmon MA and Schlessinger J: Cell signaling by receptor tyrosine kinases. Cell 141: 1117-1134, 2010.

23. Zhou D, Pan G, Zheng C, Zheng J, Yian L and Teng X: Expression of the RON receptor tyrosine kinase and its association with gastric carcinoma versus normal gastric tissues. BMC Cancer 8: $353,2008$.
24. Brechbuhl HM, Kachadourian R, Min E, Chan D and Day BJ: Chrysin enhances doxorubicin-induced cytotoxicity in human lung epithelial cancer cell lines: the role of glutathione. Toxicol Appl Pharmacol 258: 1-9, 2012.

25. Khan MS, Devaraj H and Devaraj N: Chrysin abrogates early hepatocarcinogenesis and induces apoptosis in N-nitrosodiethylamine-induced preneoplastic nodules in rats. Toxicol Appl Pharmacol 251: 85-94, 2011.

26. Ahad A, Ganai AA, Mujeeb M and Siddiqui WA: Chrysin, an anti-inflammatory molecule, abrogates renal dysfunction in type 2 diabetic rats. Toxicol Appl Pharmacol 279: 1-7, 2014.

27. Samarghandian S, Afshari JT and Davoodi S: Chrysin reduces proliferation and induces apoptosis in the human prostate cancer cell line pc-3. Clinics 66: 1073-1079, 2011.

28. Khoo BY, Chua SL and Balaram P: Apoptotic effects of chrysin in human cancer cell lines. Int J Mol Sci 11: 2188-2199, 2010.

29. Zandarashvili L, Vuzman D, Esadze A, Takayama Y, Sahu D, Levy Y and Iwahara J: Asymmetrical roles of zinc fingers in dynamic DNA-scanning process by the inducible transcription factor Egr-1. Proc Natl Acad Sci USA 109: E1724-E1732, 2012.

30. Kwon O, Soung NK, Thimmegowda N, Jeong SJ, Jang JH, Moon D-O, Chung JK, Lee KS, Kwon YT and Erikson RL: Patulin induces colorectal cancer cells apoptosis through EGR-1 dependent ATF3 up-regulation. Cell Signal 24: 943-950, 2012.

31. Kanazashi S, Hata D, Ishigami T, Jung EY, Shintaku N, Sumimoto S, Heike T, Katamura K and Mayumi M: Induction of phosphatidylinositol turnover and EGR-1 mRNA expression by crosslinking of surface IgM and IgD in the human B cell line B104. Mol Immunol 31: 21-30, 1994.

32. Perkins ND: Integrating cell-signalling pathways with NF-кB and IKK function. Nat Rev Mol Cell Biol 8: 49-62, 2007.

33. Gilmore TD: Introduction to NF- $\kappa \mathrm{B}$ : players, pathways, perspectives. Oncogene 25: 6680-6684, 2006.

34. Kim S and Joo Y-E: Theaflavin inhibits LPS-induced IL-6, MCP-1, and ICAM-1 expression in bone marrow-derived macrophages through the blockade of NF- $\mathrm{B}$ and MAPK signaling pathways. Chonnam Med J 47: 104-110, 2011.

35. Narasimhan M and Ammanamanchi S: Curcumin blocks RON tyrosine kinase-mediated invasion of breast carcinoma cells. Cancer Res 68: 5185-5192, 2008.

36. Ha SK, Moon E and Kim SY: Chrysin suppresses LPS-stimulated proinflammatory responses by blocking NF- $\mathrm{KB}$ and JNK activations in microglia cells. Neurosci Lett 485: 143-147, 2010.

37. Chen C-C, Chow M-P, Huang W-C, Lin Y-C and Chang Y-J: Flavonoids inhibit tumor necrosis factor- $\alpha$-induced up-regulation of intercellular adhesion molecule-1 (ICAM-1) in respiratory epithelial cells through activator protein-1 and nuclear factor- $\mathrm{kB}$ : structure-activity relationships. Mol Pharmacol 66: 683-693, 2004. 